\title{
DIE TOEKOMS VAN DIE AFRIKAANSE LEWENSTYL IN DIE NUWE WERELD
}

\section{Inleiding}

$\mathrm{U}$, as vooraanstaande Afrikaners, het seker almal 'n week of twee gelede, toe die Beurs in 'n windstilte gelê het, aandele gekoop. Dan het $\mathbf{u}$ voldoen aan die eerste groot verandering in die Afrikaanse lewenstyl van ons nuwe wêreld - sakebewustheid. Ek wens ek was dertig jaar jonger om met u op hierdie wittebrood van die ontwikkelende Suid-Afrika te gaan.

\section{Styl}

In 'n tyd van stylloosheid en vormlose nivellering is 'n mens bly om weer die woord styl te hoor en oor lewenstyl te besin.

Lewenstyl in die verband waarin dit hier bespreek word, het moontlik veelal betrekking op uiterlike vorme en patrone. 'n Mens durf egter nie uit die oog verloor dat uiterlike vorme en patrone ' $n$ innerlike oorsprong het nie. Dit is ' $n$ gevoel en sin vir en 'n opvatting van waardes wat in uiterlike gestaltes gekonkretiseer word. Die uiterlike is en bly derhalwe wesenlik 'n afspieëling van innerlike gebeure.

' $t$ is al zoo van buiten, 't is al zoo van bin',

't ligt alles daar bloot op mijn handen.

\section{Die nuwe wereld en sy media}

Dit lyk my nuttig om te begin by die nuwe wêreld waarin ons reeds leef, en waarin ons by voortduring steeds intiemer sal leef.

Wat en hoedanig is hierdie "nuwe wêreld?"

Dit is die wêreld wat in die kwarteeu sedert die Tweede Wêreldoorlog in aansyn gekom het. Sy vernaamste kenmerk is vryheid, sy tweede kenmerk is gelykheid; sy derde kenmerk is broederskap. Met ander woorde, dit is ' $n$ nuwe belydenis van 'n leuse en slagspreuk wat aan die einde van die agttiende eeu die Franse Rewolusie afgevuur het. Die nuwe wêreld is in sy wortels dus reeds oud; sy jongste gestalte 'n aangepaste herhaling van mislukte geskiedenis. 
Dit noop 'n mens om in hierdie vroeë stadium al vas te stel dat die Prediker gelyk gehad het met sy bevinding dat daar niks nuuts onder die son is nie.

Die „liberté, egalité, fraternité" van 1789 vind sy opvallendste toepassing - en terselfdertyd sy duurste mislukking! - in die V.V.O. Daar is alle state, klein en groot, vry of onvry, gelyk en ongelyk, in broederskap of vyandskap, oënskynlik eenders en gelykwaardig. Daar hoef nie eens gesê te word welk ' $n$ bedrog en valsheid en onwerklike ergenis dit is nie.

Voorts vind die nuwe wêreld gestalte in die oppermagtigheid van die kreet: „power”, veral „Black Power” en „Student Power". Dit vloei op sy beurt voort uit die hoogty van liberalisme en sosialisme met hul sleepsel van permissiwiteit.

Alles is veroorloof, inbegrepe die misbruik van verdowingsmiddels, die botviering van geweld, die integrasie van ongelykes, soos verskillende rasse, die verwerping van dissipline en tug, die uitkolking van die heiligdom van die menslike liggaam en die ekshibisie en eksploitasie van seks. In hierdie sake het veral Amerika, maar seer seker ook Engeland en ander lande van Europa, 'n dieptepunt van toelaatbaarheid bereik. Wat eens heilig en onaantasbaar geag was, soos bv. die Britse Koningshuis, het saam met die boek, die tydskrif, die toneel en die film 'n verbrande aarde en 'n slagveld van verwoesting geword.

Ons wat by die sensuur betrokke is en daagliks aanskou hoe elke nuwe deurbraak van naakte seks, homoseks, LSD"trips", cowboy-skiet-en-donder-films - nota bene, nou ook al uit Italië! - en ander uitwasse van permissiwiteit om binnelating teen ons poorte beuk: ons, sê ek, is in staat om te oordeel tot watter laagtes van verwording die Westerse beskawing gesink het.

Dit is in enkele breë kwasstrepe die uiterstes van die "nuwe wêreld" van die hede en die toekoms.

Ek sou u ewewel onder 'n wanindruk laat en 'n vertrokke beeld teken wanneer ek also op die uiterstes konsentreer.

Daar is veel meer: veel wat 'n subtieler en oënskynlik onskadeliker invloed het en wat ons land binnekom, ons mense bereik en gaandeweg daartoe bydra om die lewenskyk en lewenstyl van die Afrikaner te verander.

Dit is onvermydelik in die huidige wêreld met sy snelle en massale kommunikasies wat tyd en afstand verslind. ' $n$ 
Mens hoef slegs te verwys na die gedrukte woord en die prent, die film, die radio, die beeldradio en die geluid (musiek, sang en nou ook al seksvoorligting en vuil liedjies en grappe) op band of plaat.

Die massakommunikasiemedia word gekenmerk deur die feit dat betreklik min mense hulle beheer en met inhoud vul, terwyl mense by die miljoenetalle die mededelings ontvang. Terselfdertyd is die gewer die aktiewe agent, terwyl die ontvanger grotendeels passief is. Van hom word slegs verlang om sy aandag te gee, en selfs dít vereis nie veel inspanning nie vanweë die berekende aanbieding en die vereenvoudiging wat allerweë in die mededelings toegepas word.

In die huidige wêreld het isolasie feitlik onmoontlik geword. Aanranding op die oog, die oor, die verstand en die hart van die mens is onafweerbaar.

Ons dink miskien ons het die hipnotiserende aanslag van die beeldradio gespaar gebly. Dit is nie waar nie. Talryke spesifiek televisie-films draai in ons bioskope. Bowendien maak die tegnologie sulke snelle spronge dat ons binnekort gekonfronteer sal word met direkte ontvangs van satelliet-beeldradio, omdat die tussenproses van aarde-stasies, wat voorasnog die seine moet opvang en verwerk voordat hulle uitgesend word, uitgeskakel sal wees en regstreekse deurwerking via die uitspansel na die ontvangtoestel moontlik sal word.

\section{Veranderings in die Afrikaanse lowenstyl}

Die tockoms laat hom nie van die blad lees, en ek is geen siener nie. Dit gaan dus moeilik wees om te wagte aanpassings en veranderings te konkretiseer. Hier sal dit dus meer oor tendense as oor aanwysbare werklikhede gaan.

Die beste is om by die verlede te begin. Dan kan 'n mens aantoon hoe die Afrikaner en sommige van sy karaktertrekke en eiendomlikhede reeds verander het.

Laat my voorop stel dat die Afrikaner wesenlik 'n Hollandse tipe was. Die taaiheid, die deursettingsvermoë, die vryheidsdrif, die eiewysheid en die rondborstigheid wat die Nederlander tot vandag toe eie is, was sterk in die Afrikaner deur sy "Neêrlands bloed”. Hierdie eienskappe verklaar die bekende uitdrukking dat die boer baas op sy plaas is - ,heer van sy hoewe", in die deftiger woorde van die digter. Uit 
hierdie selfstandigheid het gegroei die verset teen oorheersing en onreg wat tot die Groot Trek en die Vryheidsoorloë gelei het; en ook nog nagewerk het in die Rebellie en die soms aktivistiese optrede van die Ossewa-Brandwag gedurende die vroeë veertiger jare.

Meer gewoon was die Nederlandse inslag merkbaar in die huisinrigting van die Afrikaner. Ons het drumpels gehad, en 'n lamp vlak bokant die voorhuistafel. (Soos die Hollanders dit nog het en moet hê om die koue buite te hou en die warmte van die lig naby die huiskring.)

Ons het reguit gepraat, soos die Hollanders nou nog met mekaar praat, reguit en soms skerp en hard, sonder dat die aangesprokene aanstoot neem.

Deur ons volledige konstitusionele en staatkundige triomf het ons baasmentaliteit sy bestaansrede verloor. Weens ons warm klimaat het ons drumpels en ons lamp bokant die tafel onnodig geword. En onder die invloed van Britse „understatement" en diplomasie, asmede die noodsaaklikheid daarvan om in ons veelvolkige en gevolglik veel-liddoringrige samelewing bedag te wees op die krenkende woord, het ons rondborstigheid verskrompel.

Die Hollanders het gebly wat hulle was; ons het van hulle af weg verander, veral gedurende die afgelope sestig jaar. Vandaar die verskynsel dat Afrikaners hulle in Holland ontuis voel.

Terselfdertyd voel Afrikaners hulle in Engeland tuis. Dit is toe te skryf aan die ander groot gebeure van die afgelope sestig jaar, te wete die angliseringsproses wat die Afrikaner in sy taal, sy sosiale gewoontes en sy gedragspatrone ingrypend verander het.

Laat ons na ons taal kyk. Reeds by my eerste besoek in 1951 aan Amsterdam het dit my getref hoe verward en effens gesteurd ek aangekyk word wanneer ek in 'n winkel, kantoor of kafee Afrikaans praat. Dis of die klerk wil-wil snap dat hy iets soos Nederlands hoor, maar dan besluit: nee, dis Engels, en my op Engels antwoord. Hierdie verskynsel het my - om nou goeie Nederlands te praat - dermate gepuzzle dat ek my vriend Jan Bouws daaroor uitgevra het. Sy antwoord was 'n ontnugtering: „Weet jy dan nie dat die geluid van Afrikaans Engels klink nie?" Latere besoeke aan en 'n langerige verblyf in Nederland het die diagnose bevestig. Daar 
is geen geluidsoureenkoms hoegenaamd meer tussen Afrikaans en Nederlands nie. Die geluid van ons taal is verangliseer onherroeplik verangliseer - en wat is taal wesenlik anders as geluid?

Hierdie proses duur voort, en nou nie alleen meer in die algemene taalgeluid as sodanig nie. Ons mense het nou die gier gekry om elke nie-Afrikaanse naam en woord - sy dit Frans, Italiaans, Duits of wat ook al - op Ingels uit te spreek. Mercedes is Missiedies; Guadalcanal is Goeadelkenêl; Mimosa is Mimousa. Bremer is Bremmer; Parow is Pêrrou! Dit is 'n wonder dat ons die vadere darem nog volg en eer in gevestigde uitsprake soos Kalliedon en Kraddok. Laat niemand nou teëwerp dat die Hollanders stellig die grootste taalsondaars is omdat hulle sedert ruim 25 jaar elke nuwe woord en term heelhuids uit Engels en Amerikaans oorneem en nie eens probeer om dit te vertaal nie. Dan is my antwoord: Ja, maar die struktuur en die uitspraak van die Nederlandse taal het diesnieteenstaande ongeskonde gebly. Hulle klank die basterwoorde nie Engels nie, maar Nederlands: hulle sê nie kompieuter nie, maar kompuuter; nie Laaifbôi nie, maar Lievebooi.

Dit is ondenkbaar en gewis onbegonne om met 'n veldtog van purisme die suiwerheid van die Afrikaanse taalgeluid te restoureer. Bewusmaking teen geluidsanglisering is die enigste hoop teen verdere agteruitgang.

Die taal is 'n lewende organisme. Ons sal sy groei en verandering nie kan stuit nie, en moet dit seker ook nie eens probeer doen nie. Veeleer moet verjonging en vernuwing op die grondslag van eiesoortige struktuur en idioom aangemoedig word, terwyl ons die vertroue koester dat die jeug die skeppende genie sal openbaar om 'n tóg sigself wysigende taal in wese Afrikaans te hou.

By die Afrikaanse taal staan ek 'n posie stil omdat dit ons ooilammetjie is - die een en enigste unikum van ons geestesbesit; die enkele eie kenteken wat ons apart stel en van alle ander nasies onderskei.

Kyk, ons reken ons geskiedenis en ons godsdiens ook as ons eie. Maar in der waarheid deel ons hierdie twee met ander. Die geloof is geen Afrikaanse monopolie nie, hoewel ons mag hoop en bid dat ons hierdie arke der behoudenis nooit sal verloor nie.

Die geskiedenis is in veel ruimer mate ons eie, ofskoon 
ons die maak daarvan te danke het aan botsing met ander. Die geskiedenis is bestem om die rigsnoer en inspirasie van die volk te wees. Dit is onmisbaar, en onkunde daarvan 'n growwe versuim, indien ons op die wortel daarvan wil voortstoel. Nou is dit egter 'n betreurde feit dat dit vir die geslag wat tel en steeds meer gaan tel, die jeug en reeds ook die middeljariges, grotendeels 'n geslote boek is. Uit eie ervaring weet Afrikaners van tot ongeveer 35 jaar oud niks van die gebeurtenisse wat tot die jaar 1947 plaasgevind het nie. Hulle ken niks van die aandrifte, die vuur, die veronregting, die behoefte wat tot die staatkundige omwentelings van 1948 tot 1961 gelei het nie. Hulle mis elke bewuste en organiese verband daarmee. Vandaar die fasiele oorgang tot 'n nuutgevonde sg. Suid-Afrikanisme wat dreig om die spesifieke Afrikanereiendomlikheid te laat vervaag. Daar is geen begrip meer van 'n olienhoutboom waaruit jukskeie gekap word nie; veeleer van 'n eikeboom waaruit krieketkolwe gemaak word.

\section{Roeping en identiteit}

Wat sou die Afrikaner opnuut van sy roeping en identiteit sterk bewus kan maak, en 'n vasberadenheid en trots by hom kan wek wat hom in die verlede sal laat soek na die koers van die historiese lyn vir sy hede en sy toekoms?

Sal dit kom uit sy ekonomiese voorspoed... uit die „affluent society" wat die afgod én die geesteskorrosie van hierdie tyd is?

Sal dit kom uit die swynedraf van sekseksplosie, seksekshibisionisme en sekseksploitasie in publikasie en film? Uit die dekadensie van ou Westerse beskawingswaardes miskien?

Kan hierdie dinge van weerstuit 'n aggressiewe reaksie ontketen en tot 'n herwaardering en weeraanvaarding van beproefde waardes lei?

Dit is nie onmoontlik nie. Daar is reeds tekens dat die gewone mense van Amerika en Europa begin rem; en die merkwaardige is dat die reaksie by die jeug begin intree.

Modes en giere swel en daal soos die golwe van die see. Dit het in die verlede gebeur en dit sal gewis weer gebeur dat ' $n$ lewensideologie en ' $n$ beskawingspatroon wat sy vloedhoogte bereik het, allengs vereb. Dit is vrywel onvermydelik dat die liberalisme met sy oordrewe aksente op persoonlike 
vryheid en groepsmag die versadigingspunt sal bereik en aan walging sal vergaan; en dat daarop ' $n$ weer toenemend op die spits gedrewe konservatiseringsproses sal intree. Nogtans is dit te voorsien dat dinge nog slegter kan word voordat hulle begin verbeter. ' $n$ Mens moet maar afwag.

Ek meen die geskieclenis leer dat die Afrikaner op sy swakste is wanneer dit met hom goed gaan; en op sy sterkste wanneer dit met hom sleg gaan. Die beste in die volk, sy murg en sy pit, kom te voorskyn wanneer hy aangeveg word.

Dit is geen ydelheid en geen lughartigheid wat 'n mens tot die besef bring dat 'n volk sy krisisse broodnodig het nie. Die proses van geleidelike ontpersonalisering en identiteitsverlies kan in 'n oogwink omkeer indien Suid-Afrika te doen sou kry met 'n felle, behoorlik voorbereide terroriste-aanslag; of met 'n konfrontasie met 'n V.V.O.-,,aanwesigheid" seg in Suidwes-Afrika. Dit kan ook anders gebeur, op een of meer van die skynbaar volstrek onverwagte maniere waarvan die geskiedenis leer.

Elke geslag het 'n krisis nodig as die volk nie pap moet word nie, as die pit in hom moet bly.

Dan, dan twyfel ek nie dat die Afrikaner toornend en strydend orent sal kom soos hy is, homself, in sy onverwerklike en onbesoedelde gestalte van tye her.

Dit sou nutteloos wees om jou die werklikhede te ontveins. By voortdurende orde, stilte en voorspoed is die Afrikaner besig om sienderoë te verander. Hy word Suid-Afrikaner; hy word selfs wêreldburger; hy sal dit al hoe meer word in ' $n$ wêreld wat die kommunikasies klein maak en in 'n volkeredom wat die wêreldmode en die wêreldmening eenders fatsoeneer.

Voor die einde van hierdie eeu sal die ou Afrikaner die nuwe Afrikaner nouliks nog herken. Die gelykskawingsmag is sterker as die behoudende kragte.

In sulke omstandighede is dit die kern wat tel. As die kern, die binnefonteintjie in die hart, maar wesenlik Afrikaans is, dan sal daar 'n saadpit van Afrikanerskap bewaar bly en groei wanneer sy oomblik kom.

Daar is gesê, ek meen deur Groen van Prinsterer: „In ons isolement ligt onze kracht". In hierdie wêreld baat dit egter nie om isolement te predik nie. Isolement het onhaalbaar 
ons die maak daarvan te danke het aan botsing met ander. Die geskiedenis is bestem om die rigsnoer en inspirasie van die volk te wees. Dit is onmisbaar, en onkunde daarvan ' $n$ growwe versuim, indien ons op die wortel daarvan wil voortstoel. Nou is dit egter 'n betreurde feit dat dit vir die geslag wat tel en steeds meer gaan tel, die jeug en reeds ook die middeljariges, grotendeels ' $n$ geslote boek is. Uit eie ervaring weet Afrikaners van tot ongeveer 35 jaar oud niks van die gebeurtenisse wat tot die jaar 1947 plaasgevind het nie. Hulle ken niks van die aandrifte, die vuur, die veronregting, die behoefte wat tot die staatkundige omwentelings van 1948 tot 1961 gelei het nie. Hulle mis elke bewuste en organiese verband daarmee. Vandaar die fasiele oorgang tot 'n nuutgevonde sg. Suid-Afrikanisme wat dreig om die spesifieke Afrikanereiendomlikheid te laat vervaag. Daar is geen begrip meer van 'n olienhoutboom waaruit jukskeie gekap word nie; veeleer van 'n eikeboom waaruit krieketkolwe gemaak word.

\section{Roeping en identiteit}

Wat sou die Afrikaner opnuut van sy roeping en identiteit sterk bewus kan maak, en ' $n$ vasberadenheid en trots by hom kan wek wat hom in die verlede sal laat soek na die koers van die historiese lyn vir sy hede en sy toekoms?

Sal dit kom uit sy ekonomiese voorspoed... uit die „affluent society" wat die afgod én die geesteskorrosie van hierdie tyd is?

Sal dit kom uit die swynedraf van sekseksplosie, seksekshibisionisme en sekseksploitasie in publikasie en film? Uit die dekadensie van ou Westerse beskawingswaardes miskien?

Kan hierdie dinge van weerstuit 'n aggressiewe reaksie ontketen en tot 'n herwaardering en weeraanvaarding van beproefde waardes lei?

Dit is nie onmoontlik nie. Daar is reeds tekens dat die gewone mense van Amerika en Europa begin rem; en die merkwaardige is dat die reaksie by die jeug begin intree.

Modes en giere swel en daal soos die golwe van die see. Dit het in die verlede gebeur en dit sal gewis weer gebeur dat ' $n$ lewensideologie en 'n beskawingspatroon wat sy vloedhoogte bereik het, allengs vereb. Dit is vrywel onvermydelik dat die liberalisme met sy oordrewe aksente op persoonlike 
vryheid en groepsmag die versadigingspunt sal bereik en aan walging sal vergaan; en dat daarop 'n weer toenemend op die spits gedrewe konservatiseringsproses sal intree. Nogtans is dit te voorsien dat dinge nog slegter kan word voordat hulle begin verbeter. ' $n$ Mens moet maar afwag.

Ek meen die geskiedenis leer dat die Afrikaner op sy swakste is wanneer dit met hom goed gaan; en op sy sterkste wanneer dit met hom sleg gaan. Die beste in die volk, sy murg en sy pit, kom te voorskyn wanneer hy aangeveg word.

Dit is geen ydelheid en geen lughartigheid wat 'n mens tot die besef bring dat 'n volk sy krisisse broodnodig het nie. Die proses van geleidelike ontpersonalisering en identiteitsverlies kan in 'n oogwink omkeer indien Suid-Afrika te doen sou kry met 'n felle, behoorlik voorbereide terroriste-aanslag; of met 'n konfrontasie met 'n V.V.O.-,,aanwesigheid" seg in Suidwes-Afrika. Dit kan ook anders gebeur, op een of meer van die skynbaar volstrek onverwagte maniere waarvan die geskiedenis leer.

Elke geslag het 'n krisis nodig as die volk nie pap moet word nie, as die pit in hom moet bly.

Dan, dan twyfel ek nie dat die Afrikaner toornend en strydend orent sal kom soos hy is, homself, in sy onverwerk. like en onbesoedelde gestalte van tye her.

Dit sou nutteloos wees om jou die werklikhede te ontveins. By voortdurende orde, stilte en voorspoed is die Afrikaner besig om sienderoë te verander. Hy word Suid-Afrikaner; hy word selfs wêreldburger; hy sal dit al hoe meer word in 'n wêreld wat die kommunikasies klein maak en in 'n volkeredom wat die wêreldmode en die wêreldmening eenders fatsoeneer.

Voor die einde van hierdie eeu sal die ou Afrikaner die nuwe Afrikaner nouliks nog herken. Die gelykskawingsmag is sterker as die behoudende kragte.

In sulke omstandighede is dit die kern wat tel. As die kern, die binnefonteintjie in die hart, maar wesenlik Afrikaans is, dan sal daar 'n saadpit van Afrikanerskap bewaar bly en groei wanneer sy oomblik kom.

Daar is gesê, ek meen deur Groen van Prinsterer: „In ons isolement ligt onze kracht". In hierdie wêreld baat dit egter nie om isolement te predik nie. Isolement het onhaalbaar 
geword. Die stryd is teen eenderswording en gelykvormigheid. Vandag lê ons krag in andersheid.

\section{Die toekoms}

Ek is nie twyfelmoedig nie. Ek het 'n onverslaanbare geloof in die jeug. Ons besit 'n enorme reserwe aan talent en vermoë. Kyk maar omheen hoe ons jong Afrikaners presteer: nie net persone van inbors en karakter soos Gary Player, Dawie de Villiers, Karen Muir en Bruce Dalling op die sportveld nie, maar ook die aanwassende leërskaar van stemmig en donker geklede jong predikante, sakemanne, bedryfsleiers, hoogleraars en onderwysers wat besig is om ' $n$ volk van die toekoms innerlik weerbaar te hou, ' $n$ jong land tot duiselingwekkende hoogtes te ontwikkel, en Suid-Afrika tot 'n welwillende en voelbare invloed op hierdie kontinent te maak.

My verhandeling sou $u$ kan laat voel dat ek 'n tikkie donker kyk - hoe dan ánders, sou u kan vra, wanneer ek op soveel voltooide en voortskrydende veranderings in die Afrikaanse identiteit en lewenstyl wys?

Dit is onjuis. Ek leef - en ek glo die meerderheid van my mense leef - onder 'n sterk roepingsbesef van beskawingsplig in 'n Westerse wêreld wat sigbaar veragter in waardebesef. Suid.Afrika - en dan met name die Afrikaner - is geroepe en gewillig om die bewaarder te wees van beproefde en onverganklike waardes wat eenmaal die dekadensie van die Weste sal stuit; die draer van 'n innerlike lewenstyl wat bevryding van die stof, die materialisme en die valse gode van die liberalistiese tydvak sal bring; van 'n geloof wat soos die mosterdsaadjie, hoe ver dit ook al deur die winde van verandering weggewaai mag word, uit sy onverwoesbaar gesonde kern die steggie van 'n sterk beskawingsboom sal word.

Suid-Afrika - die Afrikaner - is bestem om te lei, om die toonaangewende mag van die toekoms te word, om ander nasies en nasiemense te versoen met 'n Afrikaanse andersheid, sodat hulle aan ons gelykvormig sal word, en nie ons aan hulle nie.

Jannie Kruger.

\section{Kaapstad.}

